\title{
Role of Zinc in Patients Presenting with Recurrent Hepatic Encephalopathy in Medical Unit of Tertiarycare Hospital Lahore
}

\section{Asma Kamal, ${ }^{1}$ Asifa Kamal, ${ }^{2}$ Naeem Afzal, ${ }^{3}$ Shazia Siddique, ${ }^{4}$ Khadija Tahir ${ }^{5}$}

\begin{abstract}
Objective: To observe the effects of zinc replacement on hepatic encephaopahty. To reducce hospital admission and heath burden by reducing episodes of recurrent hepatic encephalopathy.

Methods: This study was carried out on 160 patients presenting with hepatic encephalopathy in medical ward of services hospital Lahore. The aim of the study was to assess the role of zinc in the improvement of encephalopathy.

Results: The mean age of patients in group A was 55.78 and that in group B was 56.88years. There was significant difference in mean value of hepatic encephalopathy grade in both groups A and B after 3 months of follow up (p.value 0.027) indicating zinc is beneficial in treatment of hepatic encephalopathy.

Conclusion: Our study showed that zinc replacement improved outcome in patients with Hepatic encephalopathy.

Key words: Hepatic encephalopathy, zinc supplementation, chronic liver disease.
\end{abstract}

\section{Introduction}

$\mathrm{C}$ irrhosis is diffuse hepatic process characterized by inflammation and regeneration leading to fibrosis. $^{1-2}$ The complications of chirrosis include HTN, ascitis, hepato reval lynd and HE. HE is spectrum of neuro pschychiatric abnormalities in patients that is liver dysfunction. ${ }^{3}$ The development of HE is explained by effects of neurotoxic substances which occurs in setting of chirrosis and portal hypertension. ${ }^{4}$ The development of HE negatively impacts patient's survival. The encephalopathy leading to hospitalization is associated with survival probability of $42 \%$ at one (01) year and 25\% at three (03) years. ${ }^{5}$ Approximately $30 \%$ patients dying of end stage liver disease experience HE approaching brain edema. ${ }^{6}$

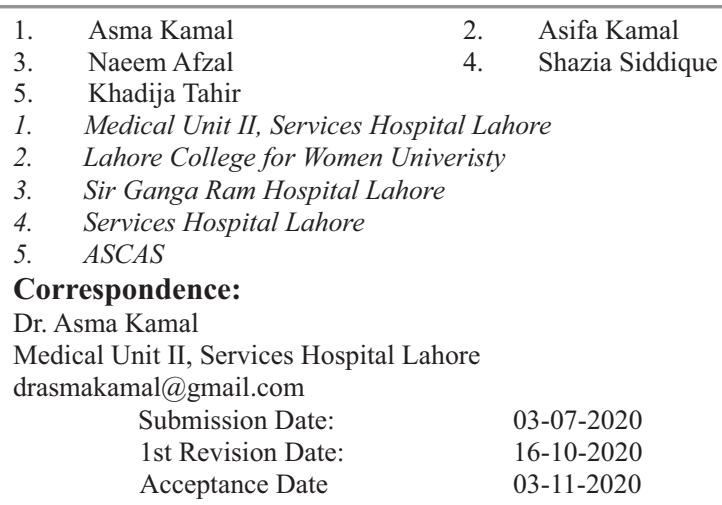

The economic burden of HE is substantial. After ascitis and GI bleed hepatic encephalopathy is $2^{\text {nd }}$ most common reason for hospital admission. Hepatic encephalopathy is also most common, possibly preventable cause of readmission. ${ }^{7}$ This results in into negative impact on employment and finances of patients and their care givers. ${ }^{9-11}$

Overt HE occurs in $30 \%$ to $50 \%$ of chirrotic patients and tends to $10 \%$ to $50 \%$ of patients with TIPS. ${ }^{2426}$ The prevalence vary between $30 \%$ to $84 \% \cdot{ }^{32-34}$ As the level of ammonia (NH3) is increased in blood, so the most common strategy is to reduce ammina production or increasing its metabolism outside the brain. To increase ammonia metabolism, one can administer LOrnithine and L-aspatate which enhances ammonia incorporation to amino acid glutamine in skeletal muscles. An earlier approach to decrease protein intake in diet lead to decreased muscles mass, so this is no more recommended now. ${ }^{12-14}$

Maintaining muscles mass is important because a chemical reaction that removes ammonia by incorporating it into glutamine can occur in the skeletal muscles. $^{15}$

Zinc deficiency is common in chirrosis and results into alter nitrogen metabolism. ${ }^{3}$ The recommended 
dietary allowance is $8 \mathrm{mg} /$ day for women and $11 \mathrm{mg} /$ day for men. The low serum zinc level in chirrotic patients is due to decrease intake, decrease absorption, decrease bio availability and increase loss (because of metabolism). ${ }^{2}$

In study of stamoulis et al in 2007, the prevalence of low serum zinc in chirrotic patients was $65.3 \%{ }^{4}$

Because low serum zinc level precipitate HE, so zinc supplementation is considered a potential therapeutic option. The oral zinc replacement improved performance on number connection test (NCT), but no evidence about other clinical and biochemical outcomes available.

In one randomized trial average HE grade was $1.3+$ 0.9 with the placebo while $0.9+0.9$ with zinc supplementation $(\mathrm{N}=39, \mathrm{P}<0.05)$ and $\mathrm{NCT}$ was $70.6+$ 29.7 seconds with the placebo while $63.6+22$ with the zinc. $^{6}$

Literature has reported that zinc supplementation is better than no zinc. There is only one local study available which showed improvement in HE by zinc supplementation.

\section{Objective}

The objective of this study is to assess the beneficial effect of zinc suppliments in the treatment of hepatic encephalopathy so the burden of recurrent admission could be reduced.

\section{Methods}

In this study 160 patients presenting with the Hepatic encephalopathy were included. Half of them (80) patients were given standard treatment for Hepatic encephalopathy i.e. Refixamin, Lactulose and branched chain amino acids were given, while the other half of patients were given standard treatment along with zinc supplements. Number connection test was carried out to assess the effect of treatment and time noted in seconds.

Inclusion Criteria: All the patients presenting with Hepatic encephalopathy were included in the study.

\section{Exclusion Criteria:}

1. Patients with organic brain disease like stroke, encephalitis, meningitis.
2. Patients with other causes of encephalopathy like uraemic encephalopathy in advanced renal failure, hypoglycaemia and severe electrolyte imbalance.

Study Design: Randomized controlled trial 160 patients with the hepatic encephalopathy were admitted through emergency and OPD over a period of 6 months. They are kept randomly in Group: A and B. Group A includes those on a standard therapy while the Group B includes standard therapy along with the zinc supplement. NCT was done during stay in the hospital at the discharge. Patients were advised to visit monthly for the follow up and NCT and recorded on the Performa.

Setting: medical unit-II of Services Hospital Lahore

Sampling Technique: Non probability consecutive sampling.

\section{Data Analysis: SPSS 20}

\section{Results}

Table 1: Percentage Distribution of Standard Treatment Group and Zinc Supplementation Treatment Group across NCT

\begin{tabular}{cccc}
\hline \multirow{2}{*}{ NCT } & \multicolumn{2}{c}{ Treatment Group } & \multirow{2}{*}{ Total } \\
\cline { 2 - 3 } & $\begin{array}{c}\text { Standard } \\
\text { Only }\end{array}$ & $\begin{array}{c}\text { Standard +Zinc } \\
\text { Supplementation }\end{array}$ & \\
\hline$<30$ & $11(13.8 \%)$ & $15(18.8 \%)$ & $26(16.3 \%)$ \\
$31-50$ & $19(23.8 \%)$ & $32(40.0 \%)$ & $51(31.9 \%)$ \\
$51-80$ & $34(42.5 \%)$ & $21(26.3 \%)$ & $55(34.4 \%)$ \\
$81-120$ & $13(16.3 \%)$ & $11(13.8 \%)$ & $24(15 \%)$ \\
Force End & $3(3.8 \%)$ & $1(1.3 \%)$ & $4(2.5 \%)$ \\
Total & $80(100 \%)$ & $80(100 \%)$ & $160(100 \%)$ \\
\hline
\end{tabular}

Figure-1 Multiple Bar Chart showing Percentage Distribution of Standard Treatment Group and Zinc Supplementation Treatment Group across NCT

Majority of patients $(18.8 \%+40 \%=58.8 \%)$ who were given zinc supplementation along with standard treatment have low level of NCT $(<50)$ as compared to those who were given only standard treatment.

Table 2: Comparison of NCT Across Standard Treatment and Zinc Supplementation Treatment Using Mann Whitney UTest.

\begin{tabular}{cccc}
\hline Treatment Type & $\begin{array}{c}\text { Mean Rank } \\
\text { of NCT }\end{array}$ & $\begin{array}{c}\text { Mann- } \\
\text { Whitney U }\end{array}$ & $\begin{array}{c}\text { P- } \\
\text { value }\end{array}$ \\
\hline Standard Treatment & 88.26 & & 0.027 \\
Zinc Supplementation & 72.74 & 2579.5 & \\
\hline
\end{tabular}


Table 3: Comparison of NCT across Standard Treatment and Zinc Treatment Using Mann-Whitney U Test (Stratified for Gender and Age)

\begin{tabular}{lcccccc}
\hline & & n & $\begin{array}{c}\text { Mean Rank of NCT } \\
\text { on Standard Therapy }\end{array}$ & $\begin{array}{c}\text { Mean Rank of NCT Zinc } \\
\text { Supp. \& Standard Therapy }\end{array}$ & $\begin{array}{c}\text { Mann- } \\
\text { Whitney U }\end{array}$ & P-value \\
\hline \multirow{2}{*}{ Gender } & Male & 106 & 58.71 & 48.29 & 1128.5 & 0.069 \\
& Female & 54 & 30.09 & 24.91 & 294.5 & 0.206 \\
\multirow{2}{*}{ Age } & $35-45$ & 20 & 11.53 & 7.40 & 22.0 & 0.197 \\
& $46-55$ & 48 & 28 & 22 & 210.0 & 0.126 \\
& $>55$ & 92 & 49.50 & 43.63 & 922.5 & 0.273 \\
\hline
\end{tabular}

Majority of patients (34.4\%) have NCT 51-80 irrespective of treatment groups.

Average rank for zinc supplementation is lower as compared to standard that indicates that there is improvement in the NCT for adding Zinc supplementation along with standard treatment. Difference in the NCT is significant among the two groups (pvalue=0.027).

Table 4: Comparison of NCT for Treatment with Zinc Supplementation Using Mann-Whitney U Test across Gender and Age.

\begin{tabular}{cccccc}
\hline & & n & $\begin{array}{c}\text { Mean Rank } \\
\text { of NCT }\end{array}$ & Test & $\begin{array}{c}\text { P- } \\
\text { value }\end{array}$ \\
\hline Gender & Male & 53 & 41.54 & Mann-Whitney & 0.557 \\
& Female & 27 & 38.46 & U Test=660.5 & \\
Age & $35-45$ & 5 & 35.30 & Kruskal Wallis & 0.174 \\
& $46-55$ & 28 & 34.91 & Test=3.502 & \\
& $>55$ & 47 & 44.38 & & \\
\hline
\end{tabular}

Mean rank for zinc supplementation group has thoroughly lower value for various categories of gender and age as compared to standard treatment group. P-value for zinc supplementation and standard treatment is not significantly different for all categories of gender and age.

Effect of zinc supplementation on NCT is not significantly different among male and female (p-value= 0.557). Similarly it has not significantly different effect on NCT for three age groups ( $\mathrm{p}$-value $=0.174$ ).

\section{Discussion}

It has been shown that zinc which is a trace metal is deficient in patients with chronic liver disease and is involved in metabolic abnormalities primarily pertaining to ammonia which can be alleviated by zinc replacement4.Zinc is an important, cheap and readily available mineral having many effects in $\mathrm{HCV}$ related cirrhotic patients. HE is characterized at the neurophysiological level by disturbed corticocortical and corticomuscular coupling causing primary gliopathy. ${ }^{16}$ Ammonia is a key pathophysiological factor in HE. ${ }^{17}$ Zinc supplementation has shown to reduce ammonia levels in experimental animals and humans through hepatic urea synthesis stimulation and glutamine synthesis in skeletal muscles. ${ }^{18}$ Several reports describe zinc supplementation improving psychometric performance with a reduction in blood ammonia level in HE patients. ${ }^{3}$ In addition, combinations of zinc and conventional therapies such as a proteinrestricted diet including BCAA preparation or lactitol have been reported as effective therapies for HE. Hayashi et al. ${ }^{19}$ reported that combination treatment with BCAA and zinc supplement decreased blood ammonia level more than BCAA treatment alone in cirrhotic patients during the study period.

According to a recent meta-analysis three studies reported data on number connection test; all three showed an improvement in performance in the zinc group compared to placebo or standard therapy. This improvement suggests a beneficial effect of oral zinc in encephalopathy patients. These findings were also similar to the findings of our study as we found improved performance on the patients of encephalopathy patients with the use of zinc..$^{20-22}$ According to Takuma et al, in their study, zinc supplementation in addition to standard treatment clearly demonstrated improved liver function and $\mathrm{HE}$ in decompensated liver cirrhosis. ${ }^{6}$ Although the studies show improvement in HE but in Pakistan, limited data was available. One study at Allied Hospital Faisalabad compared the HE outcome during hospital stay of one week between standard treatment and with zinc along standard treatment which showed improvement. ${ }^{23-24}$ While another study at the same hospital showed improvement in HCV viral load when treated with 
zinc. ${ }^{25}$ In our study we have given zinc for three month period and assessed the improvement via NCT. In our study 160 patients were participated including 80 in each group. Those replaced with the zinc show improvement in NCT with $p$ value of 0.027 .

In gender distribution males show more response to therapy as compared to females but the difference is not significant. This might e because of more number of males in the study. Our females do it early according to NCT rank.

Age wise patients with the age of $46-55$ years show more response followed by age 35-45 years and more than 55 years respectively. Although this difference is not significant with the $\mathrm{p}$ value 0.174 but it do exist.

\section{Recommendations}

As many studies show improvement with the zinc replacement along with the standard therapy, so keeping in view the health burden of decompensated liver disease one of which is HE results into repeated admissions. So zinc supplementation seems to be effective treatment for $\mathrm{HE}$ along with standard therapy to treat it. However more follow up studies should be conducted at other hospitals as well, so the large data could be analyzed and treatment be implemented.

\section{List of Abbreviations}

CLD: chronic liver disease

BCAA: Branched chain amino asides

HE: Hepatic encephalopathy

NCT: Number connection tests

\section{Authors Contribution}

AK: Main Author

AK: Statistical Analysis

SS: Write-up of Paper

NA: Helped in write-up

KT: Computerized write-up and editing

\section{References}

1. Centre TNC: Review Manager (RevMan). 50th edition. Copenhagen: The Cochrane Collaboration; 2010 .

2. Haussinger D, Schliess F: Pathogenetic mechanisms of hepatic encephalopathy. Gut 2008, 57:1156-1165.
3. Binesh N, Huda A, Thomas MA, Wyckoff N, Bugbee M, Han S, Rasgon N, Davanzo P, Sayre J, Guze B, et al: Hepatic encephalopathy: a neurochemical, neuroanatomical, and neuropsychological study. J App Clin Med Physics/Am Coll Med Physics 2006, 7:8696.

4. Butterworth RF: Neurotransmitter dysfunction in hepatic encephalopathy: new approaches and new findings. Metab Brain Dis 2001, 16:55-65.

5. Norenberg MD: Astrocytic-ammonia interactions in hepatic encephalopathy. Sem Liver Dis 1996, 16: 245-253.

6. Haussinger D, Laubenberger J, Vom Dahl S, Ernst T, Bayer S, Langer M, Gerok W, Hennig J: Proton magnetic resonance spectroscopy studies on human brain myo-inositol in hypo-osmolarity and hepatic encephalopathy. Gastroenterol 1994, 107:14751480.

7. Aschner M: The functional significance of brain metallothioneins. FASEB J 1996, 10:1129-1136.

8. Kruczek C, Gorg B, Keitel V, Pirev E, Kroncke KD, Schliess F, Haussinger D: Hypoosmotic swelling affects zinc homeostasis in cultured rat astrocytes. Glia 2009, 57:79-92.

9. Kobashi-Margain RA, Gavilanes-Espinar JG, Gutierrez-Grobe Y, Gutierrez- Jimenez AA, ChavezTapia N, Ponciano-Rodriguez G, Uribe M, Mendez Sanchez N: Albumin dialysis with molecular adsorbent recirculating system (MARS) for the treatment of hepatic encephalopathy in liver failure. Ann Hepatol 2011, 10(Suppl 2):S70-S76.

10. Schliess F, Gorg B, Haussinger D: RNA oxidation and zinc in hepatic encephalopathy and hyperammonemia. Metab Brain Dis 2009, 24:119-134.

11. Sharma P, Sharma BC: Lactulose for minimal hepatic encephalopathy in patients with extrahepatic portal vein obstruction. Saudi J Gastroenterol J Saudi Gastroenterol Assoc 2012, 18:168-172.

12. Brusilow SW, Traystman R: Hepatic encephalopathy. N Engl J Med 1986, 314:786-787. author reply 787.

13. Marchesini G, Fabbri A, Bianchi G, Brizi M, Zoli M: Zinc supplementation and amino acid-nitrogen metabolism in patients with advanced cirrhosis. Hepatology 1996, 23:1084-1092.

14. Tuerk MJ, Fazel N: Zinc deficiency. Cur Opin Gastroenterol 2009, 25:136-143.

15. Takuma Y, Nouso K, Makino Y, Hayashi M, Takahashi H: Clinical trial: oral zinc in hepatic encephalopathy. Alimen Pharmacol Therap 2010, 32:10801090.

16. Poo JL, Rosas-Romero R, Rodriguez F, Silencio JL, 
Munoz R, Bourges H, Uribe M: Serum zinc concentrations in two cohorts of 153 healthy subjects and 100 cirrhotic patients from Mexico City. Digest Dis 1995, 13:136-142.

17. Reding P, Duchateau J, Bataille C: Oral zinc supplementation improves hepatic encephalopathy. Results of a randomised controlled trial. Lancet 1984, 2:493495.

18. Bresci G, Parisi G, Banti S: Management of hepatic encephalopathy with oral zinc supplementation: a long-term treatment. Eur J Med 1993, 2:414-416.

19. Takeda A: Zinc homeostasis and functions of zinc in the brain. Biomet Int J Role Metal Ions Biol Biochem Med 2001, 14:343-351.

20. Cochrane Handbook for Systematic Reviews of Interventions Version 5.0.2. www.cochrane-handbook.org.

21. Egger M, Davey Smith G, Schneider M, Minder C: Bias in meta-analysis detected by a simple, graphical test. BMJ 1997, 315:629-634.
22. Hayashi M, Ikezawa K, Ono A, Okabayashi S, Hayashi Y, Shimizu S, Mizuno T, Maeda K, Akasaka T, Naito M, et al: Evaluation of the effects of combination therapy with branched-chain amino acid and zinc supplements on nitrogen metabolism in liver cirrhosis. Hepatol Res J Japan Soc Hepatol 2007, 37: 615-619.

23. Haussinger D: Low grade cerebral edema and the pathogenesis of hepatic encephalopathy in cirrhosis. Hepatology 2006, 43:1187-1190.

24. Morgan MY: Cerebral magnetic resonance imaging in patients with chronic liver disease. Metab Brain Dis 1998, 13:273-290.

25. Ross BD, Jacobson S, Villamil F, Korula J, Kreis R, Ernst T, Shonk T, Moats RA: Subclinical hepatic encephalopathy: proton MR spectroscopic abnormalities. Radiology 1994, 193:457-463. 